\title{
Predictive equations and multiplication factors for stature estimation using foot dimensions of an adult Nigerian population
}

\author{
Nwachukwu Mike Ibeabuchi, Emeka Ambrose Okubike* (D), Olaleye Andrew Olabiyi and Michael Ebe Nandi
}

\begin{abstract}
Background: The determination of living stature is a key component of personal identification of individuals. In this study, we developed predictive regression models and multiplication factors to reliably estimate living stature from foot length and breadth in adult Nigerian undergraduate students at the University of Lagos.

Materials and methods: The study sample comprised 400 subjects (200 males and 200 females) of Nigerian parentage, aged 18-36 years who volunteered and satisfied the inclusion criteria. Following institutional approval, anthropometric measurements of stature, foot length, and foot breadth were taken with a stadiometer, a large sliding caliper and a small sliding vernier caliper respectively according to the protocol recommended by the International Society for the Advancement of Kinanthropometry (ISAK). The data was analyzed for descriptive and inferential statistics using the SPSS statistical package version 20.
\end{abstract}

Results: Mean stature values of $176.44 \pm 6.47 \mathrm{~cm}, 164.71 \pm 6.70 \mathrm{~cm}$, and $169.80 \pm 8.79 \mathrm{~cm}$ were recorded for the males, females, and the pooled sample respectively. The mean values of the foot dimensions (right and left) in the males, females, and the pooled sample ranged from $9.49 \pm 0.73$ to $27.29 \pm 1.30 \mathrm{~cm}$. Independent $t$ test exhibited statistically significant gender differences $(P<0.05)$ for all the parameters except age, with the males having consistently higher values than the females. Paired $t$ test revealed the existence of bilateral asymmetry between right and left foot dimensions, except for the foot length in the males $(P<0.05)$. Significant positive correlation coefficients of stature with the foot length and breadth dimensions were found to range from 0.344 to 0.832 in the study. The multiplication factors computed for stature prediction from foot length and breadth ranged from 6.465 to 18.301 in the males, females, and the pooled sample.

Conclusion: This study has demonstrated that stature can be predicted from foot dimensions, with the foot length showing more accuracy and reliability than the foot breadth. The prediction models established from this study will be very useful in disaster victim identification from mutilated human remains in Nigeria.

Keywords: Stature, Foot length, Foot breadth, Forensic, Nigeria

\section{Background}

The determinants of human personal identification in forensic science include stature, age, gender, and ethnicity (Krogman and Iscan 1986; Robinson et al. 2008). In the intact corpse, stature estimation is relatively simple using primary anatomical landmarks. However, when natural disaster, traffic accidents, war, terror, and bombing occur in which victims present with dismembered or wholly

\footnotetext{
* Correspondence: okubikeemeka@gmail.com

Department of Anatomy, College of Medicine, University of Lagos, P.M.B. 12003, Lagos, Nigeria
}

(c) The Author(s). 2018 Open Access This article is distributed under the terms of the Creative Commons Attribution 4.0 International License (http://creativecommons.org/licenses/by/4.0/), which permits unrestricted use, distribution, and reproduction in any medium, provided you give appropriate credit to the original author(s) and the source, provide a link to the Creative Commons license, and indicate if changes were made. unrecognizable remains, the situation may necessitate the deployment of some other models of identification (Ekezie et al. 2014; Obafunwa et al. 2015).

Attempts at reconstructing the living stature have previously been made from the dimensions of various anatomical parts including the hand (Saxena 1984; Abdel-Malek et al. 1990; Sanli et al. 2005; Rastogi et al. 2008; Okubike et al. 2018a) and the vertebral column length (Nagesh and Pradeep Kumar 2006). Some authors have utilized footstep length (Jasuja and Manjula 1993; Jasuja et al. 1997), cephalo-facial dimensions (Krishan and

\section{SpringerOpen}


Kumar 2007), and foot length in school-age children (Grivas et al. 2008). Others, including Ozaslan et al. (2003), have examined the relationships between several lower limb dimensions and stature in an adult Turkish sample, which suggested that living stature could best be derived from various dimensions of the lower extremity. Agnihotri et al. (2007) showed that foot length is an important criterion in estimating stature among Indo-Mauritians. Ahmed (2013), while working among Sudanese Arabs, suggested that tibial length and foot length were the best predictors of stature.

The foot is one of the best-preserved fragments in mass disasters as it is often protected by footwear (Dhaneria et al. 2016), thus making it an excellent choice in forensic stature estimation. The assumption that the feet have a positive correlation with living stature is predicated on the hypothesis that larger bodies need a larger base to support weight and facilitate locomotion. Thus, dry foot bones including the metatarsals (Byers et al. 1989), talus (Holland 1995) and calcaneus (Bidmos and Asala 2005) have been used to predict stature. Incidentally, the talus in whites (Bidmos and Dayal 2003) and calcaneum in blacks (Bidmos and Asala 2004) have been used for both stature and sex determination in South Africans. Non-forensic studies on the foot have been carried out by anatomists, anthropologists, physicians, podiatrists, as well as the footwear-garment industry (Jasuja et al. 1991).

While the whole foot has been evaluated for ergonomic shoe design (Wunderlich and Cavanagh 2001; Zeybek et al. 2008), it has also been evaluated for identification of corpses, foot and shoe sizes (Jasuja et al. 1991; Giles and Vallandigham 1991; Gordon and Buikstra 1992; Ozden et al. 2005), and for footprints and foot outline (Krishan 2007, 2008). Krishan and Sharma (2007), for instance, observed that foot length estimate living stature better than foot breadth in Rajputs of Himachal Pradesh, North India. From the foregoing, it appears the attention on foot morphology and anthropometry among forensic scientists is justified. However, the argument for utilizing percutaneous foot measurement presents a number of advantages. It is relatively easy to obtain data sets from live subjects from a variety of population groups, obviating the development of regression models for predictive regression analysis for such target populations (Kanchan et al. 2008).

A number of reports on stature estimation from foot dimensions from Asia (Sanli et al. 2005; Krishan and Sharma 2007; Mansur et al. 2012; Dhaneria et al. 2016; Kim et al. 2018) and Middle East (Ozden et al. 2005; Atamturk and Duyar 2008) have recognized over the years the existence of community or ethnic diversity in foot anatomy and anthropometry. This has been attributed to a number of causative variables including climate, heredity, nutrition, lifestyle, and occupation. This observation necessitates population-specific stature prediction models from various anthropometric dimensions to be determined across the regional or ethnic divides (Shukla et al. 2017).

Despite the extensive scientific documentation on the subject globally, the record citing literature on stature prediction from direct foot dimensions among adult Nigerians is sparse (Danborno and Elukpo 2008; Ekezie et al. 2014). While some authors (Ukoha et al. 2013; Okubike et al. 2018b) have focused on footprint dimensions, few have estimated stature from percutaneous foot dimensions in the last 5 years (Oria et al. 2017).

In a populous and ethnically complex country like Nigeria, with over 450 language groups distributed over a wide and diverse geographical and ecological terrain, the milieu for bio-diversity in foot anthropometry is intense and the demand for predictive regression models is potentially huge. The young adult population in Southwest Nigeria, which includes the Lagos "mega-city," is an intense ethnic and sociocultural mix which approximates the Nigerian young adult population (Ibeabuchi et al. 2015).

This presents a population that may be described as representative of the Nigerian young adult population. The objective of this study, therefore, was (1) to describe the existing distribution of varieties of foot length and breadth dimensions, and (2) identify the presence of asymmetry and sexual dimorphism and (3) develop predictive regression models and compute multiplication factors for stature estimation, appropriate for this diverse multi-ethnic young adult Nigerian population.

\section{Materials and methods \\ Sampling}

In this cross-sectional study, 400 volunteer adult Nigerian medical students (200 males and 200 females) who reside in urban Lagos were selected using simple random sampling method. Oral interview revealed that the selected participants were born into sociocultural backgrounds wherein marriage laws in Nigeria do not restrict conjugal relationships across religious, ethnic, or social divides. Thus, allowing transmission of genetic traits from parent to offspring in a heterogeneous Mendelian manner (Hedrick 2000; Ghosh and Malik 2004). Parental roots of the participants were widespread including Yoruba, Igbo, Edo, Urhobo, Itsekiri, Ijaw, Ibibio, Efik, Hausa-Fulani, Nupe, Idoma, Igala, and Tiv. Participants were assessed to be in a generally satisfactory state of good health. Full-bred Caucasians, African, and Near East Semitics (Jews and Arabs) and Far East Asian participants were excluded. Further, the acutely ill, the physically challenged, any individuals known to be on some form of continuous medication or being in a poor state of health manifesting with overt signs of stunting, physical emaciation, and grotesque obesity were also excluded (Ibeabuchi et al. 2015). 


\section{Anthropometry \\ Equipment}

1. Stadiometer: Alpha 220, SECA $^{\text {tw }}$ (Germany)

2. Large sliding caliper: Rosscraft ${ }^{\mathrm{tm}}$ Campbell Anthropometry kit caliper 20 (Rosscraft, Canada) with two straight branches

3. Vernier caliper: Mitutoyo ${ }^{\mathrm{Tm}}$ (Japan)

\section{Techniques}

The length and breadth of both feet along with the stature of each individual were measured using the anthropometric protocols recommended by the International Society for the Advancement of Kinanthropometry (Marfell-Jones et al. 2012). All the measurements were taken by one observer in order to avoid inter-observer bias. All measurements were taken during the $0900-1300 \mathrm{~h}$ to avoid error due to diurnal variation. Anthropometric measurements defined below include:

1. Stretch stature (maximum vertical height): This was measured as the vertical distance between the vertex and the floor, where the vertex is the highest point on the head when the head is held in the Frankfort plane. The participant was required to stand barefoot in an erect posture against the wall with both feet kept close together and hands hanging down on the sides, and stature was measured using the stadiometer that was held vertically in front of the subject in mid-sagittal plane. Precautions were taken not to exert excess pressure on the vertex.

2. Foot length: This was measured as the perpendicular distance between the coronal planes of the pternion (heel) and the Akropodion, the longest toe of the foot (Fig. 1).

3. Foot breadth: This was measured as the transverse distance (Fig. 2) between the most prominent point on the medial side of the metatarsals (metatarsal-tibiale) and the most prominent point on the lateral side of the metatarsals (metatarsal-fibulare).

N.B: To facilitate accurate measurement, the caliper scale was aligned parallel to the long axis of the foot. The long axis of the foot runs through the second digit. Foot breadth was measured perpendicular to the long axis with vernier calipers as a straight distance between the metatarsal fibulare and metatarsal tibiale, with the foot in a fully stretched position.

\section{Quality control}

\section{Tester/measurer preparation}

The preparations for anthropometry included the training of the tester/measurer in anthropometric techniques to

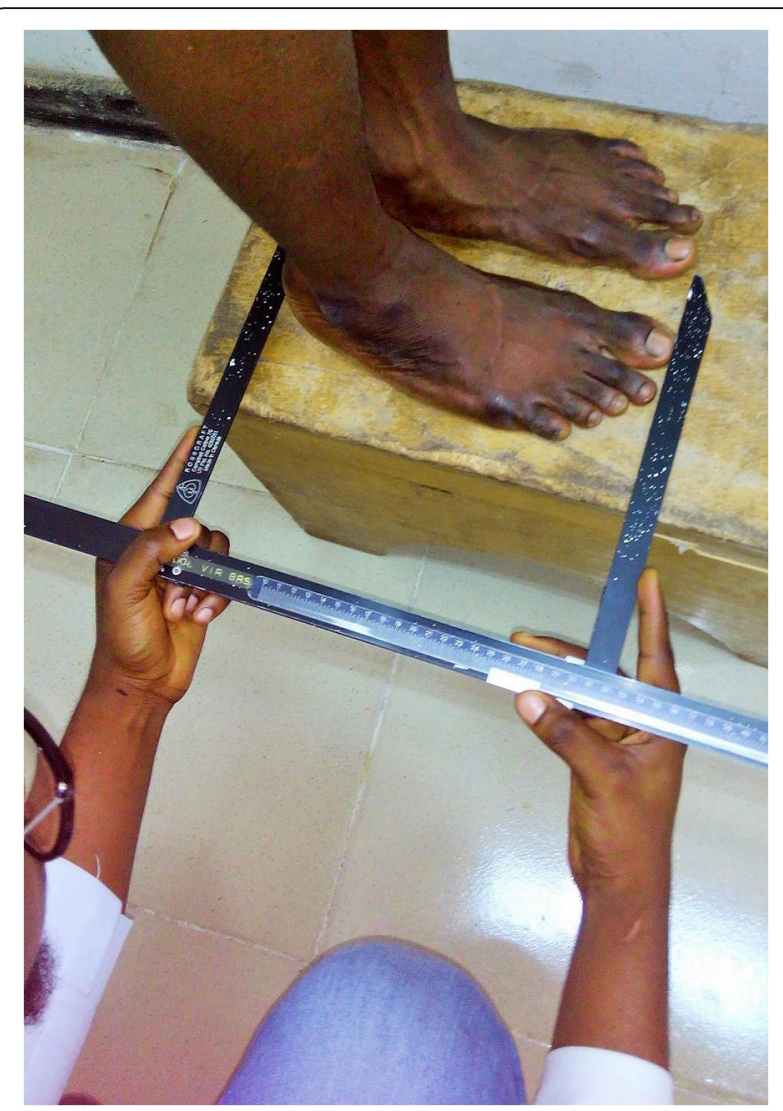

Fig. 1 Measurement of foot length

competence level consistent with anthropometry technician level 1 according to the protocol recommended by the International Society for the Advancement of Kinanthropometry (ISAK). This training was undertaken by the first author, who is an ISAK-certified anthropometry technician level 2. The tester/measurer and assistant were post-graduate students (the second and fourth authors respectively) in the Department of Anatomy, College of Medicine of the University of Lagos. The measurer had reliability testing as part of the training, aimed to achieve technical errors within internationally accepted limits. All measurements were taken by the trained tester/measurer.

\section{Measurement error}

The validity of the predictive regression models depends on the reliability of the measurements used. To determine measurement error intrinsic to this study, the two measures of validity given below were used: (1) technical error of measurement (TEM) and (2) intraclass correlation coefficient (ICC).

\section{Technical error of measurement}

This is a measure of precision or replicability of measurement. The intratester TEM was determined by taking six measurements: stature, foot length, and foot breadth, 


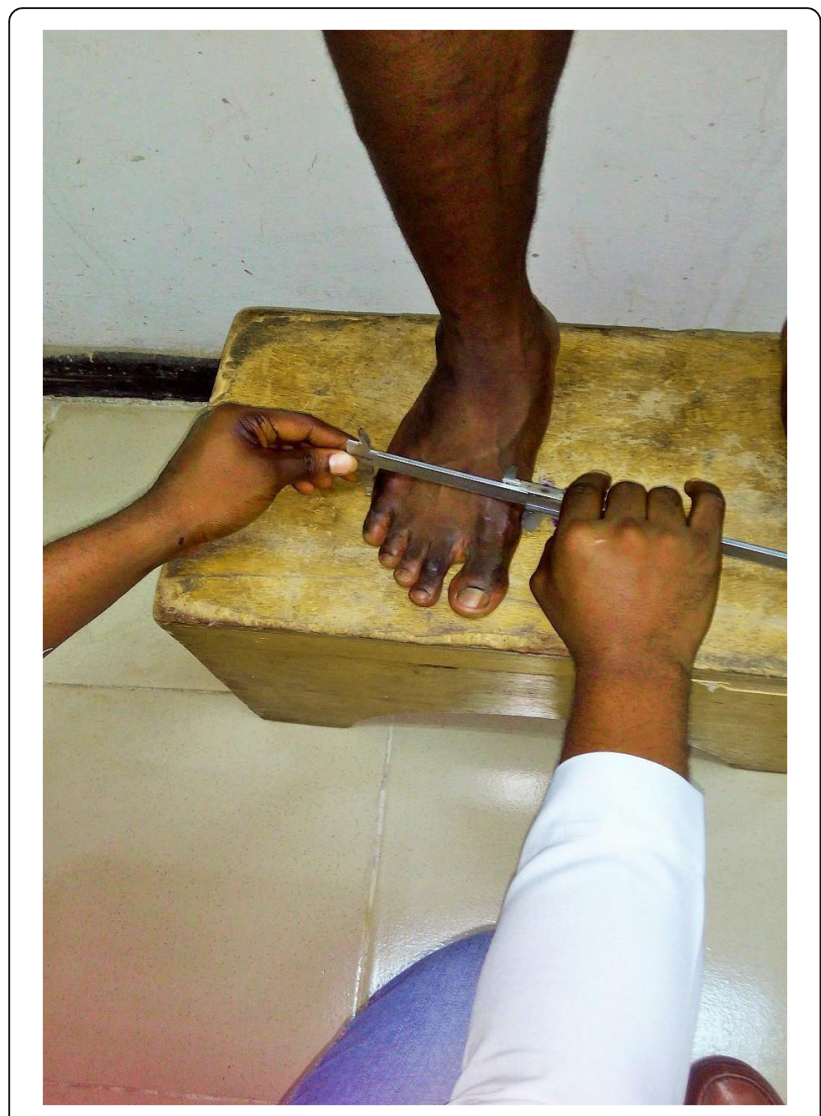

Fig. 2 Measurement of foot breadth

repeated by the tester on two participants. The measurements were then repeated "blind." The six "pairs" of measurement were compared using the equation given as follows: $T E M=\left[\sum \mathrm{d}^{2} / 2 \mathrm{n}\right]^{0.5}$.

Where " $d$ " is the difference between the first and second measures of each measurement used and " $n$ " equals the number of measurement sites on the subjects.

The intertester TEM was determined from six measurements each being taken by both the tester (second author) and the quality assurance person (first author). This "pair" of measurements was also compared using the equation given above. The subjects, variables, and measurement procedures used for the two types of TEM were the same but the tests had to be carried out independently. Since one of the testers is a certified anthropometrist, the intertester TEM was used as a measure of accuracy. The TEM provides an estimate of the measurement error in the units of measurement of the variable. This value indicates that two-thirds of the time a measurement should come within $+/-$ of the TEM.

\section{Intraclass correlation coefficient}

This is a measure of accuracy of the test measurements. The equation for intraclass correlation coefficient of reliability, $r$, is given below:

$$
r=\left(s_{o^{2}}-s_{e^{2}}\right) / s_{o^{2}}
$$

where $s_{\mathrm{o}}$ is the observed measurement variance and $s_{\mathrm{e}}$ is the error variance. In this equation, the factor $\left(s_{\mathrm{o}}{ }^{2}-s_{\mathrm{e}}{ }^{2}\right)$ represents the true measurement variance. For this study, the ICC approximated 0.90 which was considered adequate.

\section{Statistical analysis}

Data analysis was carried out with Statistical Package for the Social Sciences (SPSS) for windows, version 20.0, Armonk, New York: IBM Corporation. Data was analyzed for mean, standard deviation, standard errors of estimate (SEE), independent and paired $t$ tests. The KolmogorovSmirnov test was carried out to determine normality of the sample. Inferential statistical tests included the Student's (independent) $t$ test to compare stature, foot length, and foot breadth between the males and females and to identify evidence of sexual dimorphism in the study sample. The paired sample $t$ test further compared corresponding right and left measures for each subject to determine existence of bi-lateral asymmetry. Significance levels for differences was set at $P<0.05$ (95\% confidence interval). The Pearson's product moment correlation coefficients $(r)$, adopted as the measure of strength of the association between stature and the foot indices, was determined for both the male and female subjects, and also for the pooled sample. The coefficient of determination $\left(R^{2}\right)$ was estimated to determine how much of the variance in the dependent variable could be explained by its relationship to the other variables. Multiplication factors (MF) which, for this study, represent the mathematical relationships between stature and foot length/breadth were also determined for the subjects, and were given by the equation: M.F = stature $\div$ foot length/foot breadth. Thereafter, linear regression equations were derived as predictive models for stature estimation in this representative sample.

\section{Results}

The results are presented as tables (summarized as Tables 1, 2, 3, 4, 5, 6, and 7) and scatter graphs (Figs. 3, 4, and 5).

The Kolmogorov-Smirnov test revealed normal distribution of the data, with the test statistics found not to be statistically significant $(P>0.05)$ for all the parameters employed in the study. The significant levels (two-tailed) obtained for the male and female sample ranged from 0.057 to 0.200 .

Table 1 summarizes the descriptive and inferential statistics of age, stature, foot length, and foot breadth of the males, females, and the pooled sample. Males have consistently larger values than females for all the investigated variables. The values for the pooled sample are lower than for the males, and greater than for the females. This 
Table 1 Shows summary of the descriptive and inferential statistics of age, stature, foot length, and foot breadth of the males, females, and the pooled sample

\begin{tabular}{|c|c|c|c|c|c|c|}
\hline \multicolumn{7}{|c|}{ Descriptive and inferential statistics } \\
\hline & Measurement $(\mathrm{cm})$ & Mean & $\pm S . D$ & Range & Minimum value & Maximum value \\
\hline \multirow[t]{6}{*}{ Males $(n=200)$} & Age (years) & 25.48 & 3.18 & 18.00 & 18.00 & 36.00 \\
\hline & Stature & 176.44 & 6.47 & 31.30 & 159.90 & 191.20 \\
\hline & RFL & 27.29 & 1.30 & 6.40 & 24.10 & 30.50 \\
\hline & LFL & 27.22 & 1.36 & 7.50 & 23.10 & 30.60 \\
\hline & RFB & 10.17 & 0.59 & 2.50 & 8.90 & 11.40 \\
\hline & LFB & 10.03 & 0.56 & 2.70 & 8.60 & 11.30 \\
\hline \multirow[t]{6}{*}{ Females $(n=200)$} & Age (years) & 24.75 & 2.87 & 18.00 & 18.00 & 36.00 \\
\hline & Stature & 164.71 & 6.70 & 30.70 & 148.00 & 178.70 \\
\hline & RFL & 24.97 & 1.33 & 6.90 & 21.80 & 28.70 \\
\hline & LFL & 24.76 & 1.31 & 6.30 & 21.50 & 27.80 \\
\hline & RFB & 9.20 & 0.58 & 3.60 & 7.60 & 11.20 \\
\hline & LFB & 9.00 & 0.57 & 3.20 & 7.60 & 10.80 \\
\hline \multirow[t]{6}{*}{ Pooled sample $(n=400)$} & Age (years) & 25.12 & 3.02 & 18.00 & 18.00 & 36.00 \\
\hline & Stature & 169.80 & 8.79 & 43.20 & 148.00 & 191.20 \\
\hline & RFL & 25.98 & 1.75 & 8.70 & 21.80 & 30.50 \\
\hline & LFL & 25.83 & 1.81 & 9.10 & 21.50 & 30.60 \\
\hline & RFB & 9.61 & 0.76 & 3.80 & 7.60 & 11.40 \\
\hline & LFB & 9.49 & 0.73 & 3.70 & 7.60 & 11.30 \\
\hline
\end{tabular}

S.D standard deviation, RFL right foot length, LFL left foot length, RFB right foot breadth, LFB left foot breadth

is because the pooled sample consists of the whole study population irrespective of gender.

Table 2 summarizes gender distribution for age, stature, foot length, and foot breadth of the study population with clear evidence of sexual dimorphism within the study sample as males exhibited greater measures than females in all the investigated variables (except age). Further, the age difference between the males and females was not statistically significant.

Table 3 summaries bilateral distribution (right-left) in foot length and breadth dimensions of males, females, and the pooled sample indicating the existence of bilateral asymmetry in foot length and breadth between the females and the pooled sample. For males, there was no significant bilateral difference in foot length; however, differences in foot breadth were statistically significant at $P<0.05$.

Table 4 summarizes Pearson's correlation coefficients " $r$ " for stature with foot length and breadth of males, females, and the pooled sample. The right foot length showed greater strong positive correlation with stature than the left foot length in the males, while for females and the pooled sample, the left foot length showed greater but strong positive correlation. For the foot breadth, there was a greater moderately strong positive correlation with stature in the males than in the females, while the pooled sample showed the greatest moderately

Table 2 Shows sex differences in age, stature, foot length, and foot breadth of the study population

\begin{tabular}{lllll}
\hline Measurement $(\mathrm{cm})$ & \multicolumn{3}{l}{ Sex differences } & \\
\cline { 2 - 5 } & $t$ stat & $P$ value & \pm Mean difference & \pm Standard error of difference \\
\hline Age (years) & $1.78(\mathrm{~ns})$ & 0.075 & 0.73 & 0.40 \\
Stature & $13.41^{*}$ & 0.000 & 11.73 & 0.87 \\
RFL & $13.23^{*}$ & 0.000 & 2.32 & 0.17 \\
LFL & $13.73^{*}$ & 0.000 & 2.46 & 0.18 \\
RFB & $12.53^{*}$ & 0.000 & 0.99 & 0.07 \\
LFB & $12.46^{*}$ & 0.000 & 0.94 & 0.08 \\
\hline
\end{tabular}

$*(P<0.05)$, ns not significant, $R F L$ right foot length, $L F L$ left foot length, $R F B$ right foot breadth, $L F B$ left foot breadth 
Table 3 Shows bilateral differences (right-left) in the foot length and breadth dimensions of the males, females, and the pooled sample

\begin{tabular}{|c|c|c|c|c|c|}
\hline & \multirow[t]{2}{*}{ Paired parameter } & \multirow[t]{2}{*}{$t$ stat } & \multirow[t]{2}{*}{ Sig. level (two-tailed) } & \multicolumn{2}{|c|}{ Paired differences } \\
\hline & & & & Mean $(\mathrm{cm})$ & \pm S.E.M $(\mathrm{cm})$ \\
\hline \multirow[t]{2}{*}{ Males $(n=200)$} & RFL-LFL & 1.37 & 0.173 & 0.07 & 0.05 \\
\hline & RFB-LFB & $4.88^{*}$ & 0.000 & 0.13 & 0.02 \\
\hline \multirow[t]{2}{*}{ Females $(n=200)$} & RFL-LFL & $4.62^{*}$ & 0.000 & 0.21 & 0.04 \\
\hline & RFB-LFB & $3.31^{*}$ & 0.001 & 0.09 & 0.02 \\
\hline \multirow[t]{2}{*}{ Pooled sample $(n=400)$} & RFL-LFL & $4.36^{*}$ & 0.000 & 0.14 & 0.03 \\
\hline & RFB-LFB & $5.58^{*}$ & 0.000 & 0.11 & 0.02 \\
\hline
\end{tabular}

*(P<0.05), SEM standard error of mean, RFL right foot length, LFL left foot length, RFB right foot breadth, $L F B$ left foot breadth

strong positive correlation of stature with foot length and breadth, when genders were compared separately.

Table 5 summarized the multiplication factor values for stature estimation from both foot length and breadth in the males, females, and the pooled sample. The females showed largest multiplication factors for stature estimation from foot length and breadth when all three groups were compared.

Table 6 presents the linear regression equations for stature estimation from foot length and breadth dimensions of the males, females, and the pooled sample. The linear regression model for stature estimation from right foot length in the males had the lowest SEE value, suggesting that it has the highest reliability for predicting stature from the study parameters. The left foot length in the pooled sample showed the highest SEE value, indicating it has the least reliable model for stature prediction as compared to the foot length in the males and the females independently. Further, the right foot breadth in the males showed the lowest SEE value as

Table 4 Shows Pearson's correlation coefficients of stature with foot length and breadth of the males, females and the whole study population

\begin{tabular}{llll}
\hline & Parameters & Correlation coefficient $(r)$ & $P$ value \\
\hline Males $(n=200)$ & RFL & $0.695^{*}$ & 0.000 \\
& LFL & $0.677^{*}$ & 0.000 \\
& RFB & $0.396^{*}$ & 0.000 \\
Females $(n=200)$ & LFB & $0.406^{*}$ & 0.000 \\
& RFL & $0.678^{*}$ & 0.000 \\
& LFL & $0.714^{*}$ & 0.000 \\
& RFB & $0.357^{*}$ & 0.000 \\
Pooled sample $(n=400)$ & RFL & $0.822^{*}$ & 0.000 \\
& LFB & $0.832^{*}$ & 0.000 \\
& RFB & $0.639^{*}$ & 0.000 \\
& LFB & $0.635^{*}$ & 0.000 \\
\hline
\end{tabular}

$*(P<0.05), R F L$ right foot length, $L F L$ left foot length, RFB right foot breadth, $L F B$ left foot breadth compared to the corresponding values for the females and the pooled sample. Foot breadth in the males show the lowest SEE values as compared with the females and the pooled sample, indicating that, for this study sample, stature prediction from foot breadth is most reliable among the males. The pooled sample showed the highest overall SEE values for the foot dimensions, which suggests that stature prediction from foot dimensions in this study is more reliable when both genders were considered separately.

Table 7 summarizes the comparison of actual stature and estimated stature of randomly selected subjects using the foot dimensions and the regression equations. When the accuracy and applicability of the regression equations was verified by comparing the actual stature with the estimated stature values obtained using the foot dimensions as the independent variables, both actual and estimated stature values were closely approximated when the foot length was deployed into the regression equations, exhibiting lower error rates as compared to the estimated stature values obtained when foot breadth was deployed, suggesting that foot length is more reliable for stature prediction than foot breadth.

Figures 3, 4, and 5 depict the statistically significant linear relationships between stature and foot dimensions in the males, females, and the pooled samples. From Fig. 3, it can be observed that the overlapping trendlines for foot length in the males demonstrate the non-existence of bilateral difference between the right and left foot length, while bilateral asymmetry exists for foot breadth. In contrast, Figs. 4 and 5 showed that bilateral differences in foot length and breadth dimensions are very significant in the females and the pooled sample.

\section{Discussion}

In many instances when bodies of victims are recovered, typically, they are at different states of dismemberment and stages of decomposition. The forensic anthropologist faces the immediate dilemma of determining the true identity of the individual. When the surviving foot is all that is available in determining partial identity, to reliably 
Table 5 Multiplication factors for stature estimation from foot length and breadth of the males, females and the pooled sample

\begin{tabular}{|c|c|c|c|c|c|c|}
\hline \multirow[t]{3}{*}{ Parameter $(\mathrm{cm})$} & \multicolumn{6}{|c|}{ Multiplication factors } \\
\hline & \multicolumn{2}{|c|}{ Males $(n=200)$} & \multicolumn{2}{|c|}{ Females $(n=200)$} & \multicolumn{2}{|c|}{ Pooled sample $(n=400)$} \\
\hline & Right & Left & Right & Left & Right & Left \\
\hline Foot length & 6.465 & 6.481 & 6.596 & 6.652 & 6.535 & 6.570 \\
\hline Foot breadth & 17.349 & 17.591 & 17.903 & 18.301 & 17.669 & 17.451 \\
\hline
\end{tabular}

estimate stature from anthropometric foot dimensions, the validity of predictive regression model must rest on its simplicity of measurement, applicability, and accuracy in prediction (Kanchan et al. 2008).

We painstakingly and comprehensively documented the anthropometric protocol adopted for this study. This is because the protocol recommended by the International Society for the Advancement of Kinanthropometry is globally recognized for its simplicity of implementation, the highest quality of the equipment, the accuracy and precision of the measurements, and the strict adherence to practice standards of quality assurance through rigorous training of all members of the research team. The lead author is an ISAK certified anthropometry technician level 2 (Accreditation: Potchefstroom, South Africa, 2006).

\section{Variation in stature and foot dimensions among populations}

The mean stature and foot dimension values were recorded for the present study, with stature values ranging from $164.71 \pm 6.70$ to $176.44 \pm 6.47 \mathrm{~cm}$; and foot dimension values ranging from $9.49 \pm 0.73$ to $27.29 \pm 1.30 \mathrm{~cm}$ in the males, females, and the pooled sample. When compared with the values obtained from similar studies in other climes, it can be observed that stature and foot dimension values from the present study are greater than values reported by Ozden et al. (2005) and Zeybek et al. (2008) in Turkey, Krishan and Sharma (2007) on North Indians, Mansur et al. (2012) on adult Nepalese, Dhaneria et al. (2016) on Indian Rajasthans, and Kim et al. (2018) on South Korean males and females. These findings further validate the observation by Hossain et al. (2010) that higher values in anthropometric dimensions are obtainable in negroid populations. While these differences could be explained in part by population-specific genetic variation, varying morphological features such as foot sizes would likely depend upon geographical distribution and primary racial characteristics (Shukla et al. 2017). These inter-populational differences in anthropometric dimensions necessitate the establishment of population-specific algorithms for stature prediction from foot dimensions. More importantly, however, the finding is consistent with the Allen's rule of evolutionary physiological adaptation. In 1877, the American biologist Joel Allen had observed that the length of arms, legs, and other appendages also has an effect on the amount of heat lost to the surrounding environment. Thus, among warm-blooded animals, individuals in populations of the same species living in warm climates near the equator tend to have longer limbs than do populations living further away from the equator in colder environments due to the fact that a body with relatively long appendages is less compact and subsequently

Table 6 Shows linear regression equations for stature estimation from foot length and breadth dimensions of the males, females, and the pooled sample

Linear regression equations

\begin{tabular}{|c|c|c|c|c|}
\hline & Measurement (cm) & Linear regression equations & \pm SEE & $R^{2}$ \\
\hline \multirow[t]{4}{*}{ Males $(n=200)$} & RFL & $82.37+3.446$ (RFL) & 4.682 & 0.482 \\
\hline & LFL & $89.17+3.205(\mathrm{LFL})$ & 4.791 & 0.458 \\
\hline & RFB & $132.70+4.299$ (RFB) & 5.979 & 0.156 \\
\hline & LFB & $129.70+4.651(\mathrm{LFB})$ & 5.950 & 0.165 \\
\hline \multirow[t]{4}{*}{ Females $(n=200)$} & RFL & 79.57 + 3.409 (RFL) & 4.949 & 0.459 \\
\hline & LFL & $74.84+3.629(\mathrm{LFL})$ & 4.715 & 0.509 \\
\hline & RFB & $127.10+4.087$ (RFB) & 6.285 & 0.127 \\
\hline & LFB & $128.30+3.998(\mathrm{LFB})$ & 6.319 & 0.118 \\
\hline \multirow[t]{4}{*}{ Pooled sample $(n=400)$} & RFL & $62.46+4.131(\mathrm{RFL})$ & 5.018 & 0.676 \\
\hline & LFL & $65.37+4.043(\mathrm{LFL})$ & 4.886 & 0.692 \\
\hline & RFB & $99.33+7.331$ (RFB) & 6.783 & 0.408 \\
\hline & LFB & $97.99+7.561(\mathrm{LFB})$ & 6.812 & 0.403 \\
\hline
\end{tabular}


Table 7 Shows comparison of actual stature and estimated stature of randomly selected subjects using the foot dimensions and the regression equations

\begin{tabular}{|c|c|c|c|c|c|c|c|c|c|c|}
\hline \multirow[t]{2}{*}{$\mathrm{S} / \mathrm{N}$} & \multirow[t]{2}{*}{ Sex } & \multirow[t]{2}{*}{ Actual stature $(\mathrm{cm})$} & \multicolumn{8}{|c|}{ Estimated stature $(\mathrm{cm})$} \\
\hline & & & RFL & Er & LFL & Er & RFB & Er & LFB & Er \\
\hline 25 & M & 179.5 & 179.2 & 0.3 & 180.5 & -1 & 177.4 & 2.1 & 177.1 & 2.4 \\
\hline 53 & $\mathrm{~F}$ & 169.8 & 169.2 & 0.6 & 169.1 & 0.7 & 166.3 & 3.5 & 167.8 & 2 \\
\hline 87 & M & 181.7 & 180.5 & 1.2 & 180.1 & 1.6 & 181.2 & 0.5 & 184.1 & -2.4 \\
\hline 129 & $\mathrm{~F}$ & 177.1 & 175 & 2.1 & 176.1 & 1 & 166.6 & 10.5 & 168.2 & 8.8 \\
\hline 144 & M & 183.4 & 182.6 & 0.8 & 181.2 & 2.2 & 176.6 & 6.8 & 176.6 & 6.8 \\
\hline 184 & $\mathrm{~F}$ & 156.4 & 156.9 & -0.5 & 158.3 & -1.9 & 162.2 & -5.8 & 160.7 & -4.3 \\
\hline 230 & M & 174.6 & 180.5 & -5.9 & 179.2 & -4.6 & 176.1 & -1.5 & 175.2 & -0.6 \\
\hline 289 & $\mathrm{~F}$ & 163.7 & 164.4 & -0.7 & 164.5 & -0.7 & 170.3 & -6.6 & 169.2 & -5.5 \\
\hline 356 & M & 160.5 & 166.4 & -5.9 & 163.5 & -3 & 172 & -11.5 & 171.5 & -11 \\
\hline 392 & $\mathrm{~F}$ & 177 & 175 & 2 & 175.7 & 1.3 & 168.4 & 8.6 & 169.8 & 7.2 \\
\hline
\end{tabular}

$S / N$ serial no, $M$ male, $F$ female, $R F L$ right foot length, $L F L$ left foot length, $R F B$ right foot breadth, $L F B$ left foot breadth, Er error

has more surface area (Allen 1877). The greater the surface area, the faster body heat will be lost to the environment. This same phenomenon can be observed among humans. Hence, Africans living in the tropical rain forest tend to have larger feet.

\section{Sexual dimorphism in stature and foot dimensions}

Gender differences in stature and foot dimensions were found to be statistically significant $(P<0.05)$ in the present study, with males exhibiting greater anthropometric values than the females. Similar views have been expressed by Krishan and Sharma (2007), Zeybek et al. (2008), Uhrova et al. (2015), and Kim et al. (2018) as they all reported the existence of sexual dimorphism from their studies on Indian, Turkish, Slovak, and Korean adult populations respectively; hence, indicating that there exist statistically significant differences in foot length and breadth between the male and the female subjects in their various studies. The reason for the greater values in anthropometric dimensions in the males can be ascribed to the fact that fusion of epiphyses of bones occurs earlier in females in comparison to males, as the latter has two more years of bony growth than the former. Hormonal influences during puberty causes earlier cessation of bony growth in females than the males, as it has underlying effects on the pattern and duration of growth. The females undergo accelerated pubertal growth spurt, ending their growth faster than the males who experience more sustained growth (Ansah et al. 2017). Frey (2000) also reported that women generally tend to have a narrower heel in relation to the forefoot and narrow feet than men relative to length.

\section{Bilateral asymmetry in foot dimensions}

The present study found the foot length and breadth of the females and the pooled sample to be bilaterally asymmetric, as there exist statistically significant $(P<0.05)$ bilateral differences between the right and left sides. The foot length in the males exhibited no significant bilateral difference, though the foot breadth did. Our findings on the females, pooled sample, and the males (foot breadth) are not in line with the reports of earlier studies which

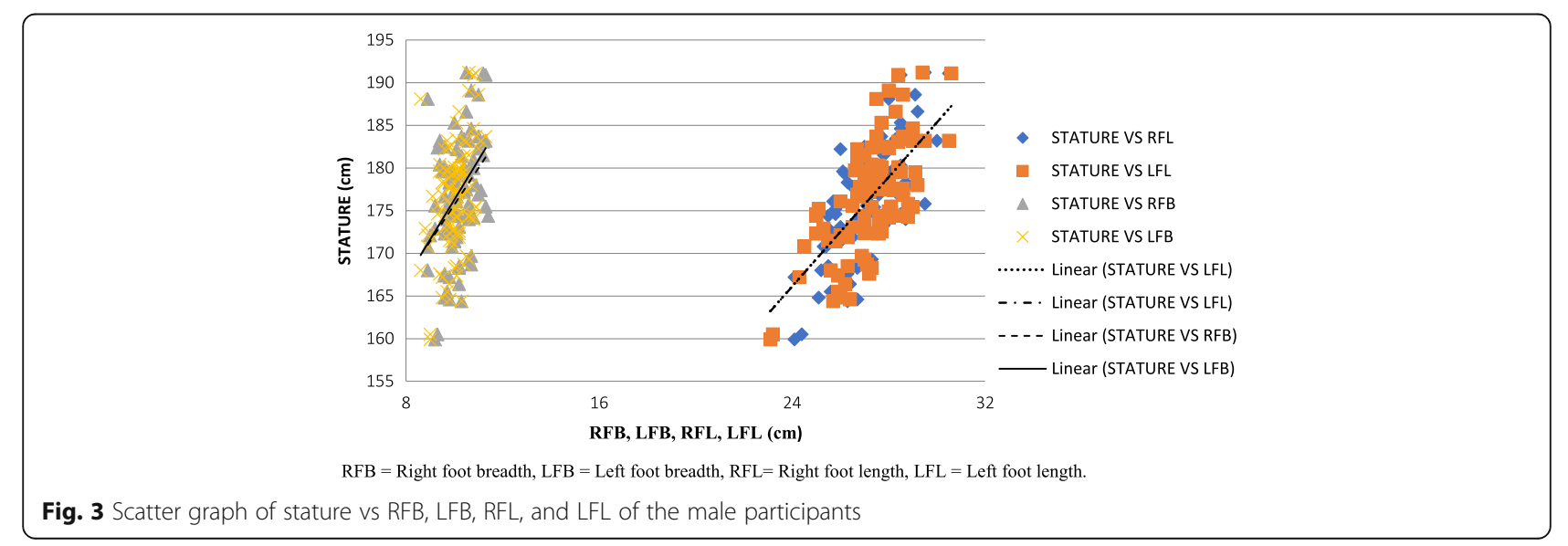




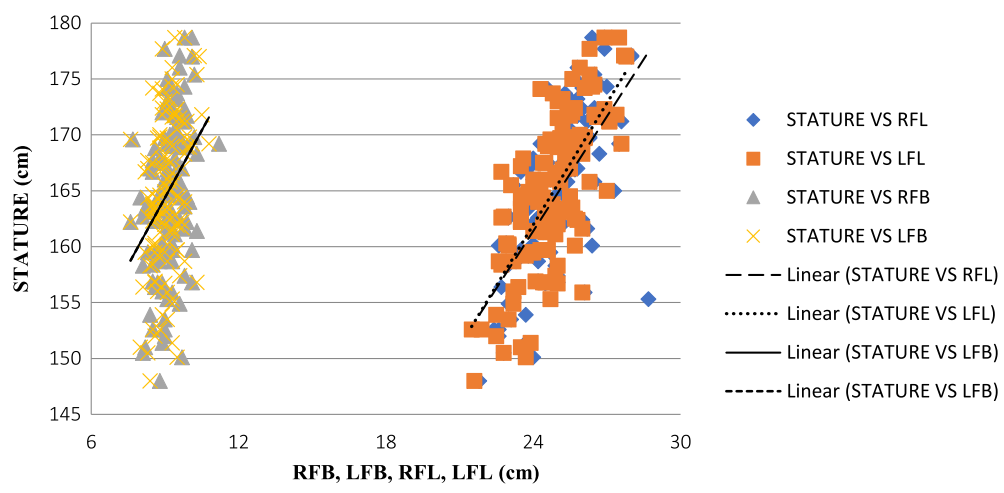

$\mathrm{RFB}=$ Right foot breadth, $\mathrm{LFB}=$ Left foot breadth, $\mathrm{RFL}=$ Right foot length, $\mathrm{LFL}=$ Left foot length

Fig. 4 Scatter graph of stature vs RFB, LFB, RFL, and LFL of the female participants

reported the non-existence of statistically significant bilateral asymmetry in foot dimensions from studies in different populations (Ozden et al. 2005; Krishan and Sharma 2007; Zeybek et al. 2008; Uhrova et al. 2015). Kanchan et al. (2008) also reported from their study on Gujjars of North India that although the mean foot dimensions were dominant on the left side in the males and on the right side in the females, the difference between the sides was statistically insignificant for all the dimensions except for foot breadth in the males. To explain this observation, it has been suggested that right-foot dominance in object manipulation and other activities including sports confers greater motor coordination, while the non-dominant side usually serves mainly for postural and stabilizing support during ordinary activity and may thus be subjected to greater mechanical load than the dominant limb, resulting in a heavier and longer non-dominant limb (Krishan et al. 2010). This theory, however, does not appear to hold for our study, as the dominant foot (right foot) showed greater anthropometric values than the contra-lateral side, except for the foot length measures in the male sample exhibiting bilateral symmetry. This bilateral symmetry in foot length for the male subjects in our study could partly be explained by the observation that more than $80 \%$ of the participants admitted to regularly engaging in football games. More than $90 \%$ of them were right-footed. This, in all probability, may have resulted in increased growth of the right foot, thus eliminating the growth preponderance of the non-dominant left foot.

\section{Correlation of stature with foot dimensions}

From this study, the foot length exhibited higher correlation coefficient values than the foot breadth in the males, females, and the pooled sample of the present study. This is in tandem with the findings of Ozden et al. (2005), Krishan and Sharma (2007), Kanchan et al. (2008), Zeybek et al. (2008), Ozaslan et al. (2012), and a host of other authors from studies predicting stature using foot dimensions. For foot length, higher correlation coefficient values than was recorded from this study were reported by Dhaneria et al. (2016) on adult Rajasthans, Krishan and Sharma (2007) on Rajputs of North India, and Uhrova et al. (2015) on adult Slovaks. This implies that the aforementioned authors recorded higher association

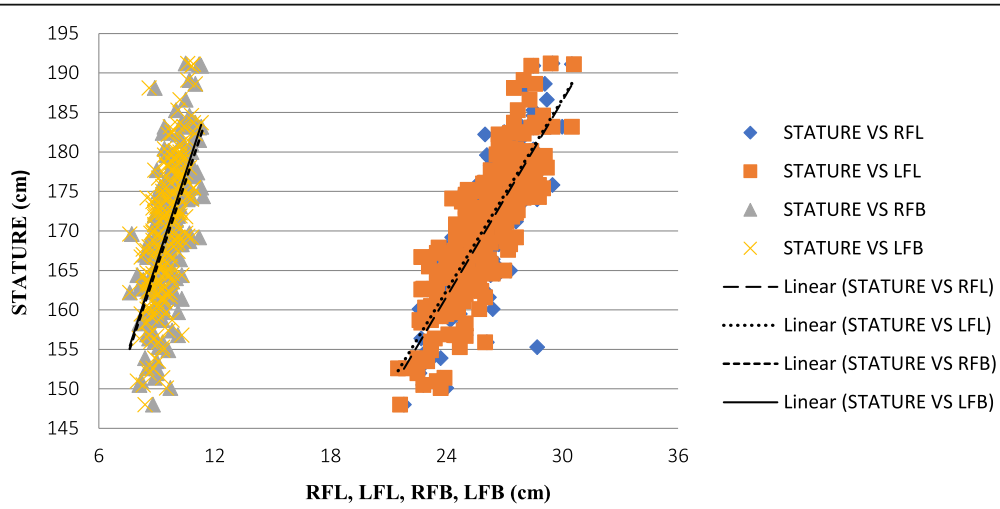

RFB = Right foot breadth, LFB = Left foot breadth, RFL= Right foot length, LFL = Left foot length

Fig. 5 Scatter graph of stature vs RFB, LFB, RFL and LFL of the pooled sample 
between stature and foot dimensions than was obtainable from the present study. When both sexes were considered separately, the present study found the maximum correlation between stature and foot length to exist for the left foot length of the female population; a finding which is congruent with that of Uhrova et al. (2015). On the contrary, Ozden et al. (2005), Krishan and Sharma (2007), and Kanchan et al. (2008) reported maximum correlations between stature and foot length in the left, right, and left foot lengths of the male sample in their respective studies.

For the foot breadth, Kanchan et al. (2008) and Dhaneria et al. (2016) recorded higher correlation coefficient values than was done for the present study, which shows that their respective studies exhibited higher association between stature and foot breadth than for the present study. Lesser correlation coefficient values of stature and foot breadth than was recorded for the present study were reported by Ozden et al. (2005) and Krishan and Sharma (2007) which indicates higher association between stature and foot breadth in the present study. The left foot breadth in the males exhibited the highest correlation in the present study when both sexes were considered separately. This is in keeping with the reports of Ozden et al. (2005) and Krishan and Sharma (2007). In contrast, Kanchan et al. (2008) in their study on adult Gujjars reported the right foot breadth in the females to have the highest correlation with stature, an observation which is not in tandem with the findings of the present study.

\section{Regression equations and multiplication factors for stature estimation}

Standard errors of estimate (SEE) values from the regression equations devised for stature prediction from foot length and breadth of the males, females, and the pooled sample of this study were recorded. For foot length, it was observed that the least SEE was shown by the right foot of the male subjects, while the left foot in the females showed the second lowest SEE value. This implies that the right foot length of the males is the most reliable parameter for stature estimation from the present study, followed by the left foot length in the female sample. In contrast, Krishan and Sharma (2007) in their study on Rajputs of North India reported that the left foot length of the female sample provided the most accurate prediction for stature, while Kanchan et al. (2008) found the right female foot breadth to be the most reliable predictor of stature in adult Gujjars, with the least SEE value. For foot breadth of the present study, it was observed that the left foot breadth in the males recorded the least SEE value, showing the highest reliability in stature prediction when foot breadth is considered. Krishan and Sharma (2007) and Kanchan et al. (2008) reported the right and left foot breadth in the female samples of their respective studies to be the best predictors of stature when the foot breadth is considered, and their findings are not congruent with the reports of the present study. Generally, the male sample of our study predicted stature more accurately using foot dimensions than the females, with a lower range of SEE values $( \pm 4.682$ to \pm 5.979 ); when compared with the females with SEE values ranging from \pm 4.715 to \pm 6.319 . This is not in agreement with the findings of Krishan and Sharma (2007) and Kanchan et al. (2008) which reported the female sample to exhibit the lowest range of SEE values from their respective studies.

Kanchan et al. (2008) reported lower multiplication factors for foot length and breadth in adult male Gujjars when compared with the values recorded for the males of the present study. However, the female Gujjars recorded higher values when compared to the female sample of the present study. This shows that adult male Gujjars have higher stature to foot dimension proportion than adult Nigerian males, while the female Gujjars have lower proportion when compared with their Nigerian counterparts. The present study also recorded greater values of multiplication factors in the females than the males, a report which is congruent with the finding of Kanchan et al. (2008) on a North Indian population.

The present study has demonstrated the utility of stature estimation standards developed from foot dimensions of an adult Nigerian population of different ethnicities in Lagos, Nigeria. This is very imperative as Lagos, the most complex metropolitan center of regional population and organization in Nigeria, the commercial capital, and the most significant city in the country, is home to many Nigerians of different ethnicities and backgrounds. The findings from this study will have important applications in the formulation of biological profiles during forensic investigations and disaster victim identification through the provision of multiplication factors and regression equations for stature prediction from foot dimensions.

\section{Conclusion}

The results obtained from the present study indicate that foot length is more reliable for stature estimation than foot breadth, as the foot length exhibited higher correlation coefficient values and lower SEE values than the foot breadth in the males, females, and the pooled sample. Therefore, it is noteworthy that once the foot is recovered in forensic contexts in Nigeria, it is advised that the foot length is preferred for stature prediction than the foot breadth.

\footnotetext{
Abbreviations

ISAK: International Society for the Advancement of Kinanthropometry; LFB: Left foot breadth; LFL: Left foot length; RFB: Right foot breadth; RFL: Right foot length; SD: Standard deviation
}

\section{Acknowledgements}

The authors wish to express sincere gratitude to the medical students of the College of Medicine of the University of Lagos, who were the study participants. 
Funding

Nil.

\section{Availability of data and materials}

Please, contact the corresponding author for data requests.

\section{Authors' contributions}

NMI: Concept and design of study, drafting of the article, revising of article for important intellectual content, final approval of the version to be published. EAO: Acquisition and interpretation of data, drafting of the article, editing and revising of article for important intellectual content, final approval of the version to be published. OAO: Data analysis, editing and revising of article for important intellectual content, final approval of the version to be published. MEN: Data recording, data analysis, revising of article for important intellectual content, final approval of the version to be published. All authors read and approved the final manuscript.

\section{Ethics approval and consent to participate}

Ethical clearance to conduct this study was sought and obtained from Health Research Ethics Committee, College of Medicine of the University of Lagos, with reference no: CM/HREC/12/16/084. The participants granted their approval prior to the commencement of measurements by giving written informed consents, such that appendage of the signature on the consent forms by the subjects served as the prerequisite for data collection.

\section{Consent for publication}

Consent to publish the images showing foot length and breadth measurements was obtained from the participant. This involved the appendage of the participant's signature on a consent publication form.

\section{Competing interests}

The authors declare that they have no competing interests.

\section{Publisher's Note}

Springer Nature remains neutral with regard to jurisdictional claims in published maps and institutional affiliations.

\section{Received: 13 March 2018 Accepted: 6 November 2018}

Published online: 19 November 2018

\section{References}

Abdel-Malek AK, Ahmed AM, el-Saharkawi SA, el-Hamid NM (1990) Prediction of stature from hand measurements. Forensic Sci Int 46(3):181-187

Agnihotri AK, Purwar B, Googoolye K, Agnihotri S, Jeebun N (2007) Estimation of stature by foot length. J Forensic Legal Med 14(5):279-283

Ahmed AA (2013) Estimation of stature using lower limb measurements in Sudanese Arabs. J Forensic Legal Med 20(5):483-488

Allen JA (1877) The influence of physical conditions in the genesis of species. Radic Rev 1:108-140

Ansah EO, Abaidoo CS, Diby T, Tetteh J, Appiah AK, Atuahene OO, Darko ND (2017) A preliminary anthropometric study of height and sex determination using percutaneous ulnar and femoral lengths. Int J Anat Res 5(1):3638-3643

Atamturk D, Duyar I (2008) Age related factors in the relationship between foot measurement and living stature and body weight. J Forensic Sci 53(6):1296-1300

Bidmos MA, Asala SA (2004) Sexual dimorphism of the calcaneus of South African blacks. J Forensic Sci 49(3):446-450

Bidmos MA, Asala SA (2005) Calcaneal measurement in estimation of stature of South African blacks. Am J Phys Anthropol 126(3):335-342

Bidmos MA, Dayal MR (2003) Sex determination from the talus of South African whites by discriminant function analysis. Am J Forensic Med Pathol 24(4): 332-338

Byers S, Akoshona K, Curran B (1989) Determination of adult stature from metatarsal length. Am J Phys Anthropol 79(3):275-279

Danborno B, Elukpo A (2008) Sexual dimorphism in hand and foot length, indices, stature-ratio and relationship to height in Nigerians. Internet J Forensic Sci 3(1):379-383

Dhaneria V, Shrivastava M, Mathur RK, Goyal S (2016) Estimation of height from measurement of foot breadth and foot length in adult population of Rajasthan. Indian J Clin Anat Physiol 3(1):78-82
Ekezie J, Anibeze C, Ikechukwu P, Akpuaka F, Anyanwu G, Onwukamuche C, Uloneme $G$ (2014) Stature estimation using right digits and palm length in Igbo population, Nigeria. Ann Bioanthropol 2:23-28

Frey C (2000) Foot health and foot wear for women. Clin Orthop Relat Res 372:32-34

Ghosh S, Malik SL (2004) A comparative study of age changes in somatotypes of Brahmin and Rajput boys of Sundarnagar, Himachal Pradesh. Anthropologist 6(1):19-23

Giles E, Vallandigham PH (1991) Height estimation from foot and shoeprint length. J Forensic Sci 36(4):1134-1151

Gordon CC, Buikstra JE (1992) Linear models for the prediction of stature from foot and boot dimensions. J Forensic Sci 37(3):771-782

Grivas TB, Milhas C, Arapaki A, Vasiliadis E (2008) Correlation of foot length with height and weight in school age children. J Forensic Legal Med 15(2):89-95

Hedrick PW (2000) Genetics of populations, 2nd edn. Jones and Bartlett Publishers, Sudbury, MA

Holland TD (1995) Estimation of adult stature from the calcaneus and talus. Am J Phys Anthropol 96(3):315-320

Hossain S, Begum JA, Banu LA, Rahman F, Akhter Z (2010) Prediction of stature from hand length and breadth: an anthropometric study on Christian Garo tribal Bangladesh females. Bangladesh J Anat 8(1):21-27

Ibeabuchi MN, Mbagwu SI, Omotayo HA, Olayemi TA, Aniah J (2015) Skeletal frame-size variations in adolescent female Nigerian school children in Lagos. Ann Bioanthropol 3:22-28

Jasuja OP, Harbhajan S, Anupama K (1997) Estimation of stature from stride length while walking fast. Forensic Sci Int 86(3):181-186

Jasuja OP, Manjula (1993) Estimation of stature from footstep length. Forensic Sci Int 61(1):1-5

Jasuja OP, Singh J, Jain M (1991) Estimation of stature from foot and shoe measurements by multiplication factors: a revised attempt. Forensic Sci Int 50(2):203-215

Kanchan T, Menezes R, Moudgil R, Kotian MS, Garg RK (2008) Stature estimation from foot dimensions. Forensic Sci Int 179:241.e1

Kim W, Kim YM, Yun MH (2018) Estimation of stature from hand and foot dimensions in Korean population. J Forensic Legal Med 55:87-92

Krishan K (2007) Individualizing characteristics of footprints in Gujjars of North India-forensic aspects. Forensic Sci Int 169(2-3):137-144

Krishan K (2008) Estimation of stature from footprints and foot outline dimensions in Gujjars of North India. Forensic Sci Int 175:93-101

Krishan K, Kanchan T, DiMaggio JA (2010) A study of limb asymmetry and its effect on estimation of stature in forensic case work. Forensic Sci Int 200:181.e1

Krishan K, Kumar R (2007) Determination of stature from cephalo-facial dimensions in a north Indian population. Legal Med 9(3):128-133

Krishan K, Sharma A (2007) Estimation of stature from dimensions of hands and feet in a north Indian population. J Forensic Leg Med 14(6):327-332

Krogman WR, Iscan MY (1986) The human skeleton in forensic medicine, 2nd edn. Charles C. Thomas, Illinois: Springfield

Mansur DI, Haque MK, Sharma K, Karki RK, Khanal K, Kharna R (2012) Estimation of stature from foot length in adult Nepalese population and it's clinical relevance. Khatmandu Univ Med J 10(1):16-19

Marfell-Jones MJ, Stewart AD, de Ridder JH (2012) International standards for anthropometric assessment. International Society for the Advancement of Kinanthropometry, Wellington

Nagesh KR, Pradeep Kumar G (2006) Estimation of stature from vertebral column length in south Indians. Legal Med 8(5):269-272

Obafunwa J, Francis A, Sunday S, Uwom O, Edmund N, William I (2015) Forensic investigation of mass disasters in Nigeria: a review. Niger Med J 56:1-5

Okubike EA, Ejimofor OC, Nandi ME, Umeasalugo KE (2018a) The predictive role of percutaneous hand length in stature estimation of an adult Nigerian population. Int J Anat Res 6(3.1):5405-5413

Okubike EA, Ibeabuchi NM, Olabiyi OA, Nandi ME (2018b) Stature estimation from footprint dimensions in an adult Nigerian student population. $J$ Forensic Sci Med 4(1):7-17

Oria RS, Igiri AO, Mathias AO, Micheal NE (2017) Regression equations for estimating stature from anthropometric measurements of foot length and breadth in adults of Efik ethnic group in Cross River state. J Exp Clin Anat 16:127-131

Ozaslan A, Iscan MY, Ozaslan I, Tugcu H, Koc S (2003) Estimation of stature from body parts. Forensic Sci Int 132(1):40-45

Ozaslan A, Karadayi B, Kolusayin MO, Kaya A, Afsin H (2012) Predictive role of hand and foot dimensions in stature estimation. Rom J Leg Med 20:41-46

Ozden H, Balci Y, Demirustu C, Turgut A, Ertugrul M (2005) Stature and sex estimate using foot and shoe dimensions. Forensic Sci Int 147(2-3):181-184 
Rastogi P, Nagesh KR, Yoganarasimha K (2008) Estimation of stature from hand dimensions of north and south Indians. Legal Med 10(4):185-189

Robinson C, Eisma R, Morgan B, Jeffrey A, Graham E, Black S, Rutty G (2008) Anthropological measurement of lower limb and foot bones using multi-detector computed tomography. J Forensic Sci 53(6):1289-1295

Sanli SG, Kizilkanat ED, Boyan N, Ozsahin ET, Bozkır MG, Soames R, Erol H, Oguz O (2005) Stature estimation based on hand length and foot length. Clin Anat 18(8):589-596

Saxena SK (1984) A study of correlation and estimation of stature from hand length, hand breadth and sole length. Anthropol Anz 42(4):271-276

Shukla RK, Lodha AS, Das S (2017) Stature estimation from footprint: a study on central Indian population. Eur J Forensic Sci 4(2):11

Uhrova P, Benus R, Masnicova S, Obertova Z, Kramarova D, Kyselicova K, Dornhoferova M, Bodorikova S, Nescakova E (2015) Estimation of stature using hand and foot dimensions in Slovak adults. Legal Med 17:92-97

Ukoha UU, Egwu OA, Ezeani MC, Anyabolu EA, Ejimofor OC, Nzeako HC, Umeasalugo KE (2013) Estimation of stature using footprints in an adult student population in Nigeria. Int J Biomed Adv Res 4(11):827-833

Wunderlich RE, Cavanagh PR (2001) Gender differences in adult foot shape: implication for shoe design. Med Sci Sports Exerc 33(4):605-611

Zeybek G, Ergur I, Demiroglu Z (2008) Stature and gender estimation using foot measurements. Forensic Sci Int 181(1-3):54 el-5

\section{Submit your manuscript to a SpringerOpen ${ }^{\circ}$ journal and benefit from:}

- Convenient online submission

- Rigorous peer review

- Open access: articles freely available online

- High visibility within the field

- Retaining the copyright to your article

Submit your next manuscript at $\boldsymbol{\nabla}$ springeropen.com 